\title{
Connections between the cochlear nuclei in guinea pig
}

\author{
Susan E. Shore ${ }^{a}$, Donald A. Godfrey ${ }^{a}$, Robert H. Helfert ${ }^{b}$, Richard A. Altschuler ${ }^{\text {b }}$ \\ and Sanford C. Bledsoe, Jr. ${ }^{b}$ \\ ${ }^{a}$ Department of Otolaryngology, Medical College of Ohio, Toledo, Ohio, ISA and ${ }^{b}$ Kresge Hearing Research Institute, University of Michigan, \\ Ann Arbor, Michigan, USA
}

(Received 9 August 1991; Revision received 26 February 1992; Accepted 9 April 1992)

\begin{abstract}
This study provides a detailed analysis of the appearances and distributions of neurons projecting from one cochlear nucleus to the other. Injections of wheatgerm agglutinin conjugated to horseradish peroxidase were made into ventral or dorsal cochlear nucleus of the guinea pig. Retrogradely labeled cells in the opposite cochlear nucleus were examined and quantified. Three major categories of labeled cells were discerned on the basis of their soma shape: elongate, round-to-oval, and polygonal. All injections resulted in widespread labeling of cells in all of these categories, but especially round-to-oval cells, in the opposite ventral cochlear nucleus and sparse labeling in the dorsal cochlear nucleus. The results suggest that there is a significant cochlear nucleus commissural projection involving heterogeneous cell types which could have diverse functions in binaural auditory signal processing.
\end{abstract}

Horseradish peroxidase-wheatgerm agglutinin; Contralateral cochlear nucleus; Ventral cochlear nucleus; Dorsal cochlear nucleus; Commissural connections; Binaural hearing

\section{Introduction}

Connections between the two cochlear nuclei were initially suggested about 20 years ago by the responses of cochlear nucleus neurons to acoustic stimulation of the contralateral ear. Many of these responses, exitatory or inhibitory in the dorsal cochlear nucleus (Mast, 1970; 1973; Young and Brownell, 1976) and inhibitory in the ventral cochlear nucleus (Pfalz, 1962; Pirsig et al., 1968; Hochfeld, 1973), had latencies compatible with one synaptic delay (Hochfeld, 1973; Mast, 1973). The commissural cochlear nucleus projection, shown in this study to be composed of heterogenous cell types, provides anatomical support for such response diversity. Our results differ from those of previous studies which have described only large, multipolar cells pro-

Correspondence to: S.E. Shore, Medical College of Ohio, Department of Otolaryngology, Toledo, OH 43699, USA. Fax: (313) 7640014.

Abbreviations: ANR - Auditory nerve root; AVCN - Anteroventral cochlear nucleus; CN - Cochlear nucleus; CPO - Caudal periolivary region; DMPO - Dorsomedial periolivary region; DPO - Dorsal periolivary region; DCN - Dorsal cochlear nucleus; MNTB - Medial nucleus of the trapezoid body; MSO - Medial superior olivary nucleus; PVCN - Posteroventral cochlear nucleus; SOC - Superior olivary complex; VCN - Ventral cochlear nucleus; VNTB - Ventral nucleus of the trapezoid body; WGA-HRP - Wheatgerm agglutinin conjugated to horseradish peroxidase. jecting to the opposite cochlear nucleus (Adams and Warr, 1976; Cant and Gaston, 1982; Wenthold, 1987).

The present study provides quantitative information in the guinea pig, regarding the appearances and locations of cells labeled with WGA-HRP after injections into portions of the opposite cochlear nucleus. Cells were categorized in terms of their soma shapes and sizes which were the features most consistently visible after the cells were retrogradely labeled with WGAHRP. Because many intracellular features were often obscured using this technique, and dendritic arborizations only partially visible, it was not possible to definitively categorize the cells according to previously defined categories. However, three easily distinguishable soma shapes were observed: round-to-oval, eiongate and polygonal (Pirsig, 1968). Labeled round-to-oval cells gave rise to thin dendrites (when visible) and were more prevalent in the rostral portions of ventral cochlear nucleus, while polygonal and elongate cells usually gave rise to thicker dendrites (when visible) and were equally prevalent in rostral and caudal ventral cochlear nucleus. By confining injections to different divisions of the nucleus, we were able to demonstrate some specificity in the connections. The projection is significant in size and one of potential major importance, involving heterogeneous cell types with somewhat specific targets, each of which could subserve a different function. 


\section{Methods}

Fifteen pigmented guinea pigs (250-400 g) were anesthetized with ketamine hydrochloride (Ketaset; 80 $\mathrm{mg} / \mathrm{kg}$ ) and xylazine (Rompun; $4 \mathrm{mg} / \mathrm{kg}$ ) administered intramuscularly. Periodic supplementation was used to maintain anesthetic levels throughout the procedure. The left cochlear nucleus was visualized, after a posterior fossa surgical approach, by aspirating a small part of the overlying cerebellum. A glass micropipette filled with $2 \%$ WGA-HRP, in phosphate buffered saline (pH 7.4), was placed under visual control on the surface of the dorsal cochlear nucleus. After the electrode placement, the brain was covered with warm mineral oil to prevent tissue desiccation and reduce brain pulsation. Evoked potentials in response to click stimulation were recorded as the electrode was advanced ventrally (Shore and Nuttall, 1985). At a depth corresponding to the maximum-amplitude evoked potential, which occurred in dorsal cochlear nucleus or ventral cochlear nucleus depending on whether the electrode was placed medially or laterally, a continuous, positive current (3-5 $\mu \mathrm{A})$ was passed through the silver recording wire for 2-15 min. After the electrode was removed, some neck muscle was applied to replace the volume of aspirated brain, dental cement was used to seal the opening, and the animal was sutured and allowed to recover. After a 24-h survival period, the animal was deeply anesthetized with sodium pentobarbital and perfused transcardially with $50 \mathrm{ml}$ of $0.05 \%$ sodium nitrite in normal saline, followed by $750 \mathrm{ml}$ of mixed aldehyde fixative (1\% glutaraldehyde and $1.5 \%$ formaldehyde in phosphate buffer, $\mathrm{pH}$ 7.4). Following their removal from the skull and postfixation for 2-4 h in the same fixative, the brainstems were immersed overnight at $4^{\circ} \mathrm{C}$ in $20 \%$ sucrose in $0.12 \mathrm{M}$ phosphate buffer, $\mathrm{pH}$ 7.4. Forty $\mu \mathrm{m}$ thick transverse frozen sections were cut containing the cochlear nuclei $(\mathrm{CN})$, superior olivary complex (SOC), nuclei of the lateral lemniscus (NLL) and inferior colliculus (IC) and reacted with 3,3'-5,5'-tetramethylbenzidine (TMB) to visualize the peroxidase (Mesulam, 1978). The reacted sections were then mounted and counterstained with neutral red (Mesulam, 1978). To avoid counting the same cell twice, every second section was studied using a Leitz Dialux microscope equipped with a drawing tube. In the sections studied, each labeled cell in the contralateral cochlear nucleus was counted and analyzed in terms of its shape and size. Soma shape was chosen as the major criterion for grouping cells be-
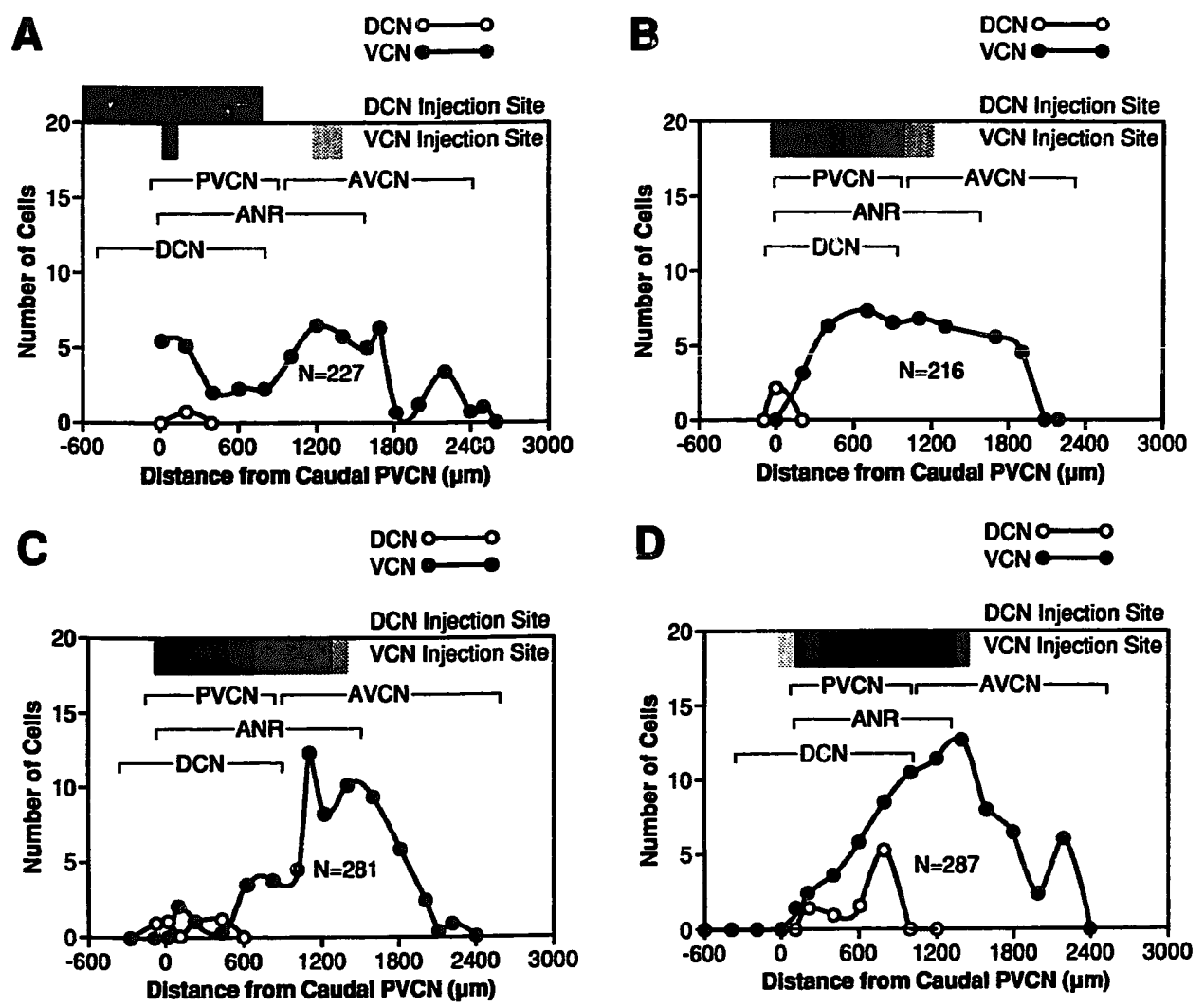

Fig. 1. Rostral-caudal locations of labeled cells in the $\mathrm{CN}$ contralateral to injections in the opposite $\mathrm{CN}$ in 4 guinea pigs with different injection sites. The number of cells found is plotted versus distance from the most caudal part of PVCN, which is set to zero. Each point is the average of three consecutive sections. The extents of the divisions of the $\mathrm{CN}$ are indicated by the brackets above each graph. The total number of labeled cells for each injection is indicated by N. The shaded area at the top represents the injection site, above the line for DCN (1A, animal 62988), and below the line for VCN sites (1B-D, animals 3288, 70688, and 32489). The density of shading reflects the intensity of tracer deposition. 
cause details of the intracellular structure were obscured by the HRP, and nissl patterns are less pronounced in guinea pig than in cat. Three distinct soma shapes were observed; round-to-oval, elongate, and polygonal. The round-to-oval group included somata whose appearance was rounded, even if one axis was longer than the other. Elongate cells had one axis sufficiently longer than the other to give the appearance of a long thin cell. Polygonal and elongate cell bodies often gave rise to large diameter dendrites whereas round-to-oval cells tended to give rise to thin dendrites. The distribution of the three groups differed; round-to-oval cells were found in more rostral locations than the other two groups which were distributed more evenly throughout the nucleus. Roundto-oval cells in this study are likely to correspond to bushy cells because of their soma shapes and characteristic distributions, while polygonal and elongate cells probably correspond to the multipolar cells described by others. Because multipolar cells are a heterogenous class and it is possible that some of them may appear as round-to-oval, no definite statements can be made about these relationships without having access to additional information. Soma size was measured as the length of the longer axis, using a calibrated eyepiece micrometer. The measurements were not corrected for tissue shrinkage which occurs during processing. To obtain the total number of cells, the counts were multiplied by two. An estimate of the total number of labeled cells in the SOC was obtained by counting those in every 5 th section and multiplying the counts by 5 (Shore et al., 1991).

\section{Results}

This study has shown the projection from contralateral cochlear nucleus to be significant, comparable in size to that from the ipsilateral lateral nucleus of the trapezoid body (Winter et al., 1988; Shore et al., 1991). Although the total number of labeled cells in the contralateral cochlear nucleus correlated with injection
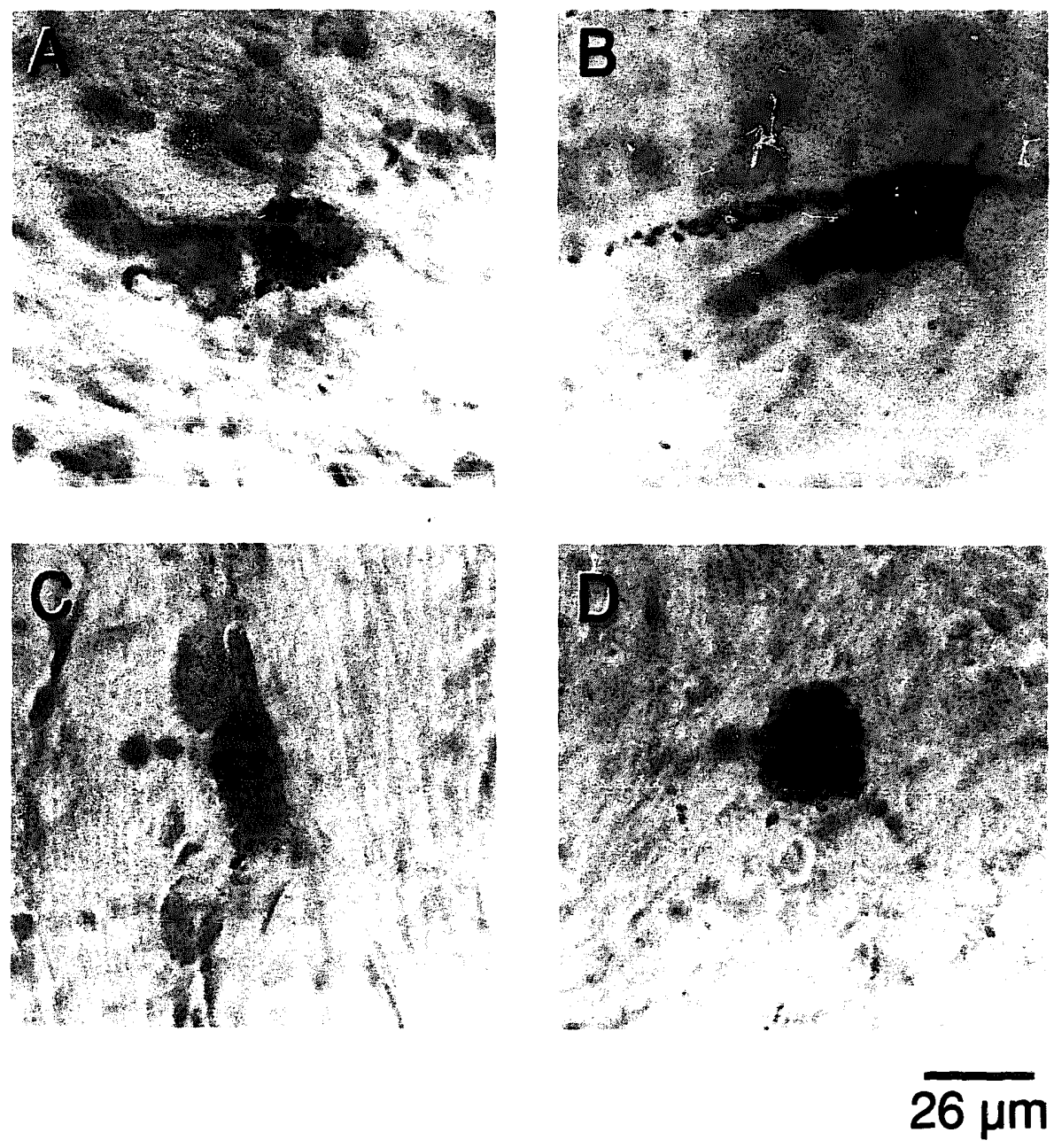

Fig. 2. A-E: Photomicrographs of the three different cell types identified to project via the cochlear nucleus commissural pathway: (A) and (D) Round-to-oval cells in AVCN at $40 \times$; (B) A polygonal cell located in PVCN at $40 \times$; (C) An elongate cell located in AVCN at $40 \times$; (E) Two lightly filled round-to-oval cells in the nerve root area shown at $25 \times$. Note the eccentrically located nuclei. (F) An gxample of one WGA-HRP injection confined to PVCN, demonstrating the containment of WGA-HRP within the cochlear nucleus. 

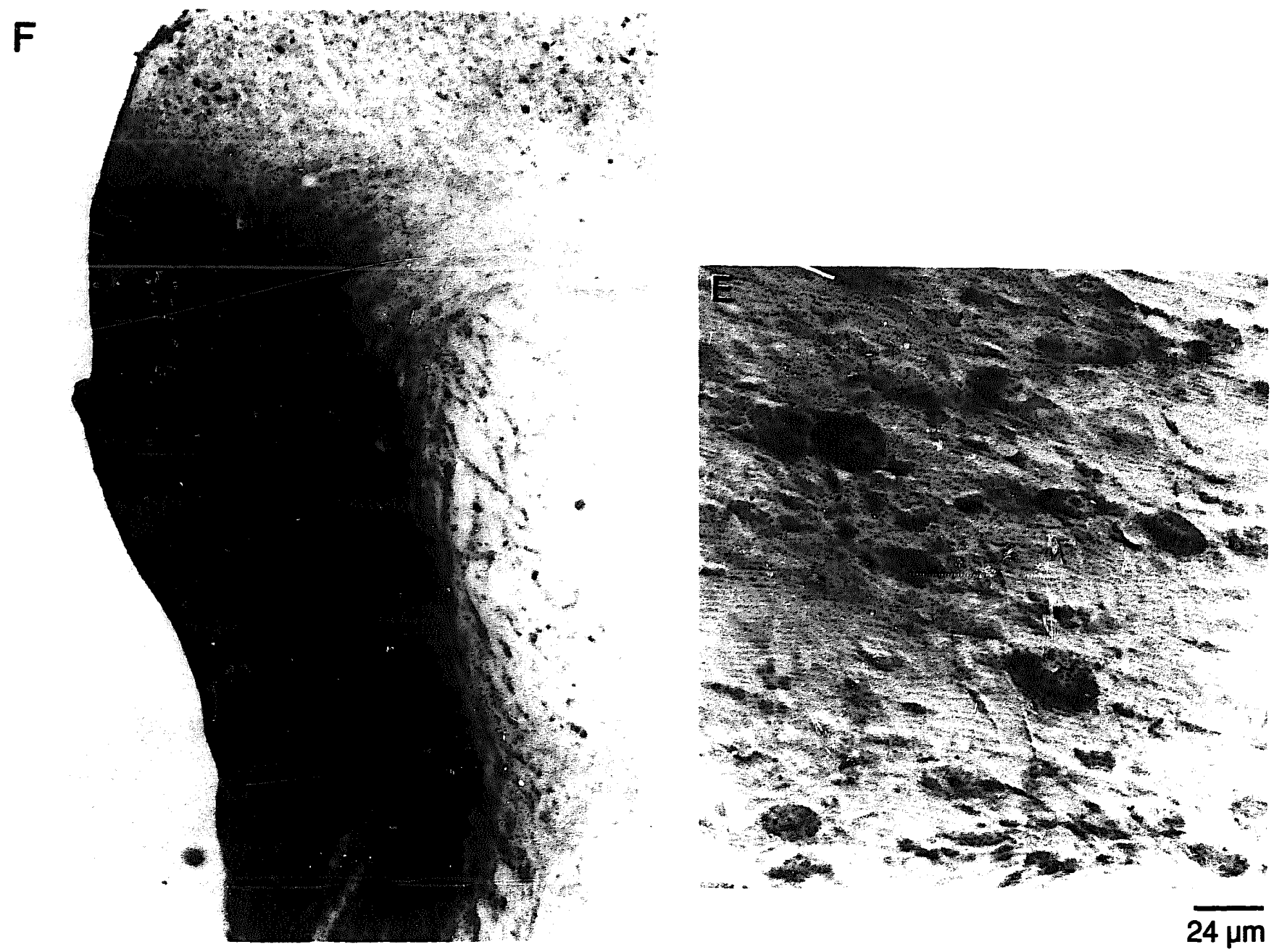

Fig. 2 (çontinued).

size, which ranged from $700 \mu \mathrm{m}$ to $4300 \mu \mathrm{m}$ in rostral-caudal extent, the distribution and types of ceils were related to the location of the injection site.

\section{Distribution of labeled cells}

Cells which project to the contralateral cochlear nucleus were located predominantly in the ventral cochlear nucleus, where they were distributed throughout its rostral-caudal extent. For large injections into dorsal cochlear nucleus, (Fig. 1A), the number of labeled cells was highest in caudal anteroventral cochlear nucleus, but was also significant in caudal posteroventral cochlear nucleus. This second concentration of cells was absent after a smaller injection into dorsal cochlear nucleus (not shown) which encompassed only its medial portion. Few labeled cells were observed in the contralateral dorsal cochlear nucleus after any dorsal cochlear nucleus injections. When injections were made in ventral cochlear nucleus with high density in the posterovental portion and little spread to the anteroventral region, labeled cells were distributed uniformly along the rostral-caudal extent of contralateral ventral cochlear nucleus (Fig. 1B). When the injection density was high in both the posteroventral and anteroventral regions, more labeled cells were seen in caudal and central anteroventral cochlear nucleus (Fig. 1C and D). Scrine cells were labeled in the dorsal cochlear nucleus after ventral cochlear nucleus injections (Fig. 3), especially if anteroventral regions were included in the injection site (Fig. 1D).

Overall, the distribution of labeled cells in contralateral cochlear nucleus suggests that the commissural pathway is comprised mainly of neurons from the ventral cochlear nucleus. The posteroventral region receives a projection from its contralateral counterpart and also the anterventral portion, while the caudal anteroventral region receives a projection from its contralateral counterpart and a smaller projection from dorsal cochlear nucleus. Virtually no projection to dorsal cochlear nucleus was observed from the contralateral dorsal cochlear nucleus itself. We are unable to make statements concerning the projections to the rostral anteroventral region since it was not included in our injection sites. 


\section{Categories of labeled cells}

The TMB procedure used in this study allowed visualization of the somata and, in many cases, proximal dendrites of labeled neurons. Since we were unable to consistently visualize dendrites or intracellular features, we could not assign cells to the categories described by other investigators (Osen, 1969; Brawer et al., 1974; Cant and Morest, 1984; Moore, 1986; Hackney et al., 1990). Instead, we measured soma size (using the long axis measurement) and described soma shape. At least 3 soma shapes could be distinguished:

Round-to-Oval.Round or oval soma, generally having only one or two visible thin dendrites. The long axis ranged from 6-35 $\mu \mathrm{m}$. Examples are Fig. 2A, D and E and Fig. 3, cells 1-5, upper right section, cells 1-8, middle right section, and cells $1-4$, lower right section.
The occurrence of labeled round-to-oval cells increased progressively towards the rostral end of ventra! cochlear nucleus, as is apparent from Fig. 3.

Elongate. Tapered som $*$ with the long axis noticeably longer than the short axis. The long axis ranged from 15-46 $\mu \mathrm{m}$. Examples are Fig. $2 \mathrm{C}$; and Fig. 4, cell 5, upper left section, and Fig. 5, cell 3, left section.

Polygonal.Polygonal soma generally having 3 or more visible thick dendrites. The long axis ranged from 8-46 $\mu \mathrm{m}$. Examples are Fig. 2B; Fig. 4, cells 2, 3 and 5, upper right section, and Fig. 5, cells 5 and 9, upper left section.

\section{Distribution of labeled soma forms}

Regardless of the injection location or size, the majority of labeled cells tended to be round-to-oval,
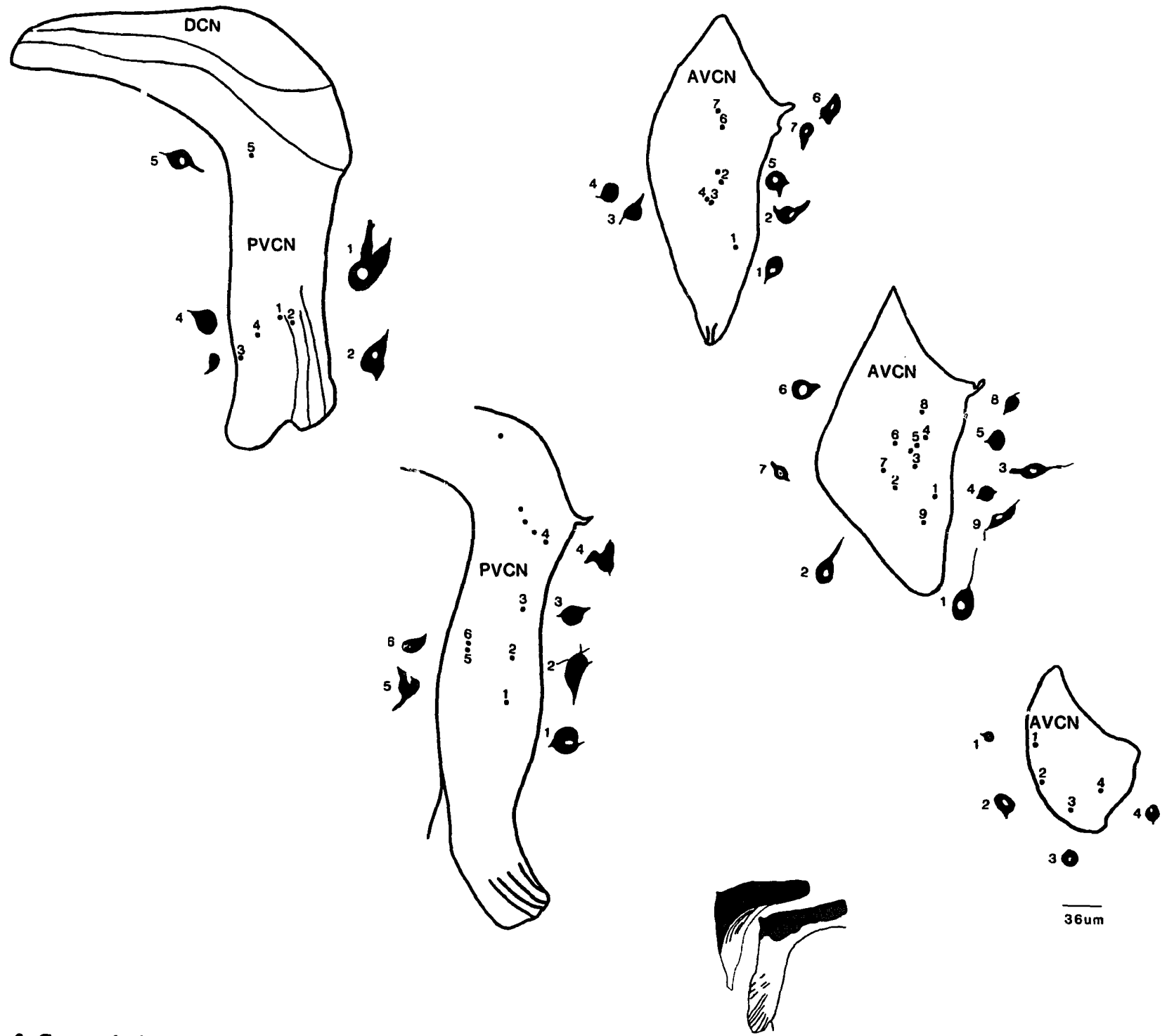

Fig. 3. Camera lucida reconstructions of serial transverse $40 \mu \mathrm{m}$ sections of the $\mathrm{CN}$. The injection site (DCN; No. 62988) is shown at lower center. The locations of labeled cells are shown as dots on each section. Enlarged drawings of well-labeled cells are shown at the perimeters of the sections, numbered to correspond to their locations. The most caudal section is at the upper left, the most rostral at the lower right. Scale bar applies to enlarged drawings of cells $(40 \times)$. 
around $20 \mu \mathrm{m}$ in size. Elongate and polygonal cells were less numerous. The labeled cells were organized topographically, with the occurrence of round-to-oval cells increasing, and polygonal and elongate cell occurrence decreasing in a caudal-to-rostral direction. There were, however, differences in the locations and distributions of these cells as a function of the injection site (Fig. 6). More round-to-oval cells were labeled in contralateral ventral cochlear nucleus, especially the anteroventral part, after injections into the dorsal as compared with ventral cochlear nucleus. The same dorsally located injections resulted in relatively larger numbers of elongate cells in the opposite anteroventral division, vs. polygonal cells in the posteroventral cochlear nucleus (compare Fig. 6A and B).

In contrast, injections into the ventral cochlear nucleus labeled elongate, round-to-oval and polygonal cells uniformly in both divisions of the contralateral cochlear nucleus, with the exception of large elongate cells ( $>36 \mu \mathrm{m}$ ), which were more numerous caudally, in the posteroventral portion (Fig. 6C and D). The large round-to-oval cells $(>26 \mu \mathrm{m})$ seen in anteroventral cochlear nucleus after injections into dorsal cochlear nucleus were rarely labeled after ventral cochlear nucleus injections.

\section{Discussion}

In this study, retrograde transport of WGA-HRP identified three groups of neurons - round-to-oval, elongate and polygonal - which project across the guinea pig brainstem from one cochlear nucleus to the other. The large WGA-HRP injections into different regions of either dorsal or ventral cochlear nucleus resulted in widespread labeling of these cell types throughout the contralateral ventral cochlear nucleus, and sparse labeling in the dorsal cochlear nucleus. The most common type of cell projecting to the opposite
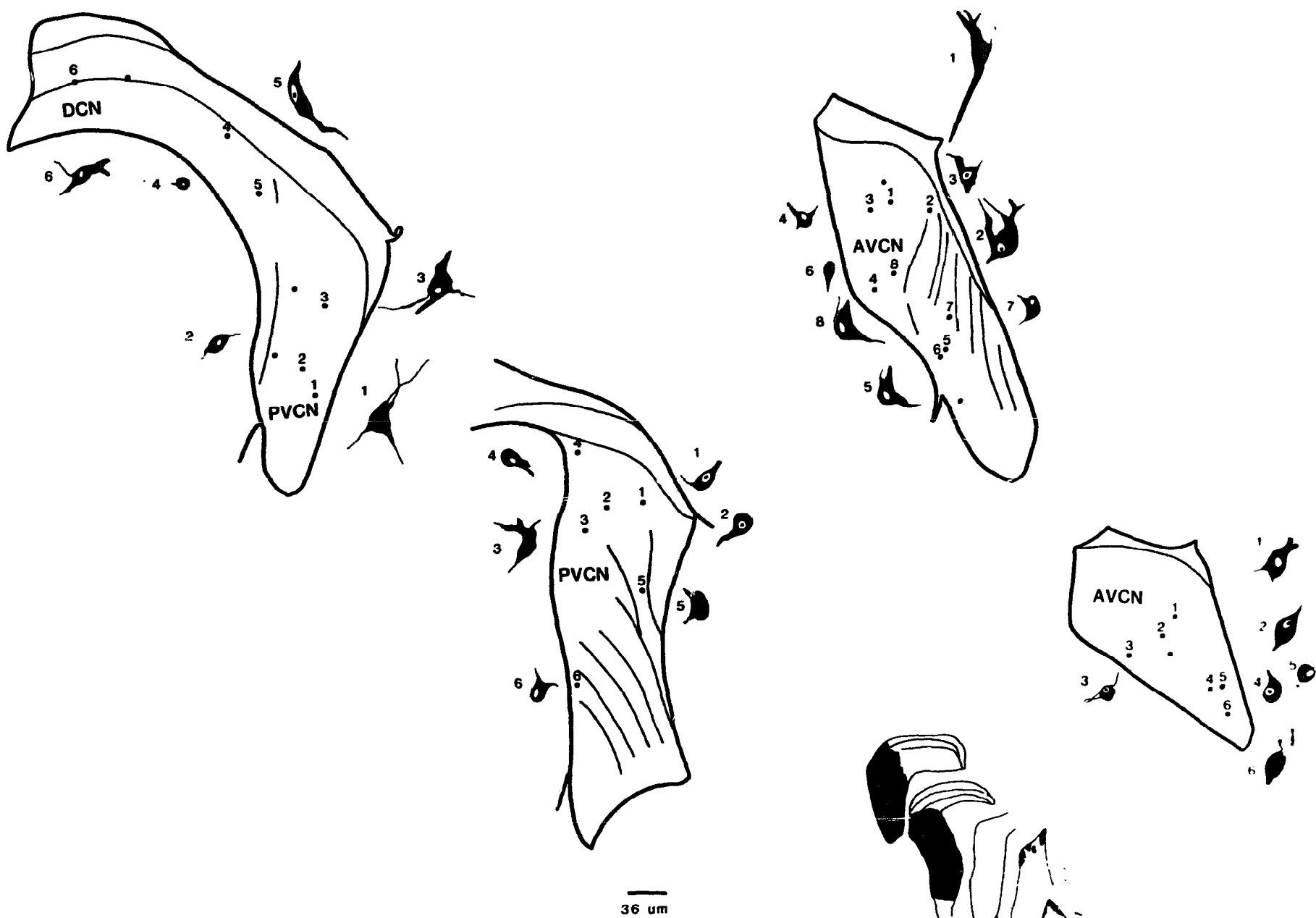

Fig. 4. Camera lucida reconstructions of serial transverse $40 \mu \mathrm{m}$ sections of the CN. The injection site (PVCN; No. 3288) is shown at lower center. The locations of labeled cells are shown as dots on each section. Enlarged drawings of well-labeled cells are shown at the perimeters of the sections, numbered to correspond to their locations. The most caudal section is at the upper left, the most rostral at the lower right. Scale bar applies to enlarged drawings of cells $(40 \times)$. 
cochlear nucleus is the round-to-oval cell, the largest of which $(>26 \mu \mathrm{m})$, in anteroventral cochlear nucleus, projects almost exclusively to the dorsal cochlear nucleus. Those betwsen 16 and $25 \mu \mathrm{m}$ in diameter in the anteroventral division project both to dorsal and ventral cochlear nucleus. In contrast, the 16-25 $\mu \mathrm{m}$ round-to-oval cells in posteroventral cochlear nucleus project more strongly to contralateral ventral cochlear nucleus. The smaller polygonal and elongate cells found in ventral divisions tend to project to the opposite dorsal cochlear nucleus, while the larger ones project more strongly to ventral cochlear nucleus. (see Fig. 7 for a more detailed summary of these findings).

We have refrained from categorizing labeled cells according to criteria designated by previous authors (eg. Osen, 1969, Moore, 1986, Cant and Morest, 1984 and Hackney et al., 1990) because intraceilular features and dendritic patterns were not always accessible using WGA-HRP. However, based on cell shape, and, when possible, the number and kinds of dendrites, and, on occasion, the location of the nucleus, we are able to suggest that our three cell categories may correspond to categories described by Cant and Morest (1984) in the cat and Moore (1986), Pirsig (1986) and Hackney et al (1990) in the guinea pig. The 'elongate' group could correspond to Pirsig's (1986) fusiform cells, Moore's (1986) 'horizontal fan' cells and Hackney et al's (1990) 'lacy, elongate cells' in the dorsal cochlear nucleus, and 'bipolar, giant' cells in dorsal cochlear nucleus and ventral cochlear nucleus. The 'polygonal' cells described here are more likely to correspond to multipolar cells (Pirsig, 1986; Cant and Morest, 1984; Moore, 1986 and Hackney et al., 1990), but also would include cells described as giant multipolar or radiate by Pirsig (1968) and Hackney et al. (1990). We have also included in this group cells which appear similar to octopus cells, based on their soma shape and thick dendrites arising from only one side of the soma. An example is cell number 5 , Fig. 5 , upper left. If this cell is compared with the octopus cells shown by Hackney et al in their Figs. 7A and 8A, and Cant and Morest in their Fig. 11-1, the similarity is easily apparent.

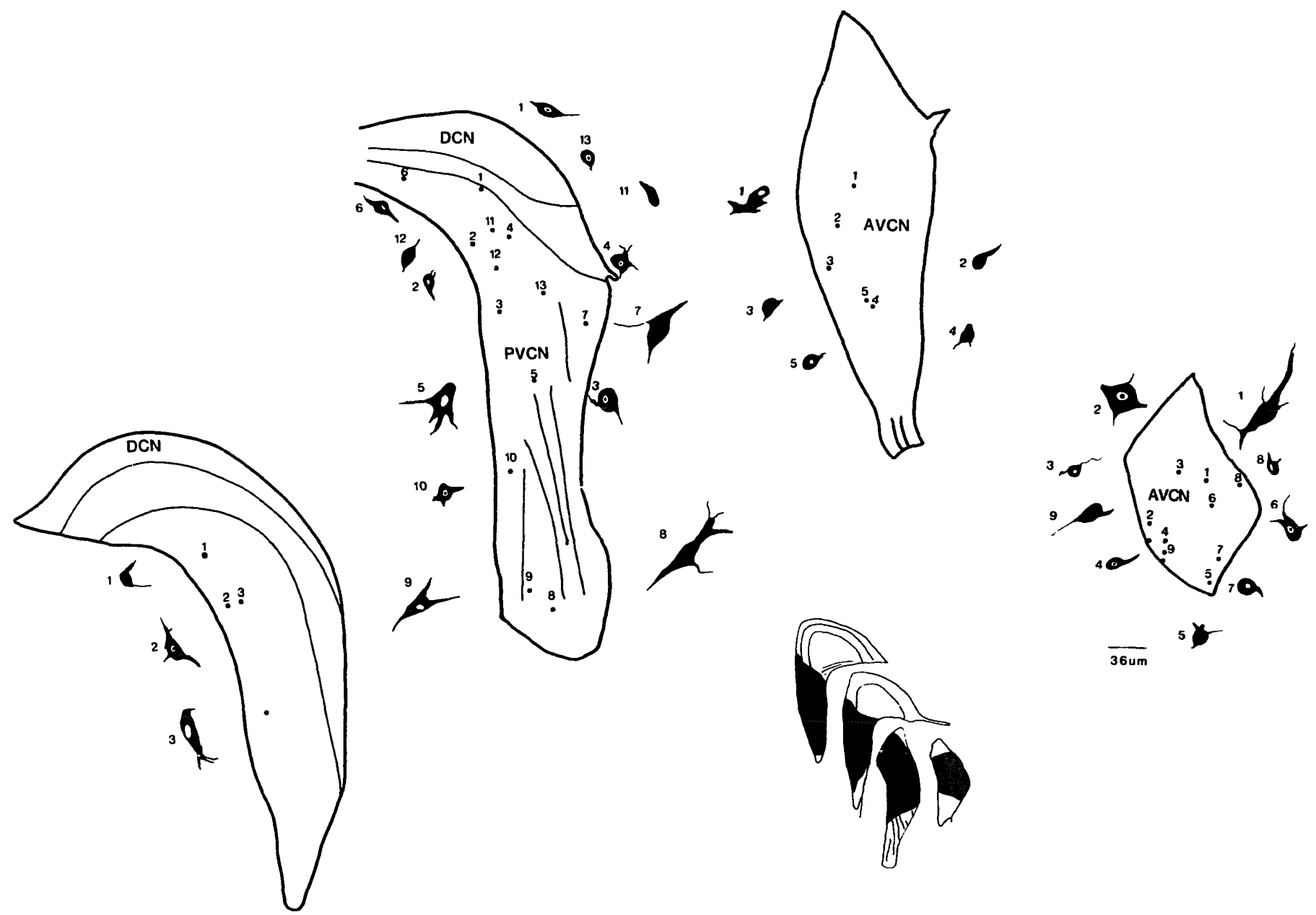

Fig. 5. Camera lucida reconstructions of serial transverse $40 \mu \mathrm{m}$ sections of the CN. The injection site (PVCN and AVCN; No. 32489) is shown at lower center. The locations of labeled cells are shown as dots on each section. Enlarged drawings of well-labeled cells are shown at the perimeters of the sections, numbered to correspond to their locations. The most caudal section is at the lower left, the most rostral at the lower right. Scale bar applies to enlarged drawings of cells $(40 \times)$. 
A

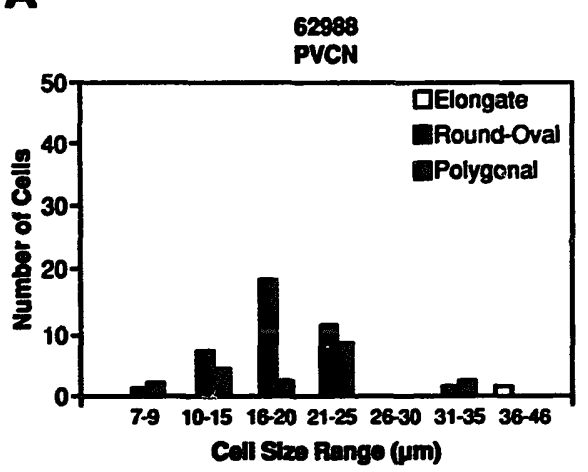

C

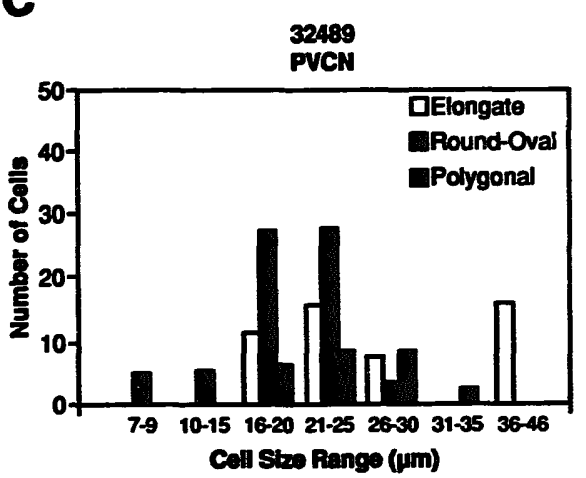

B

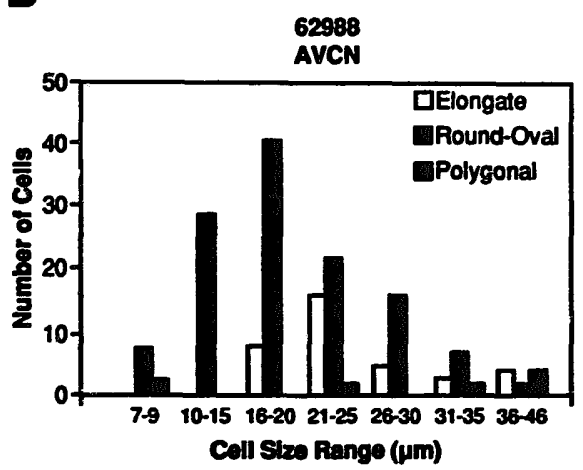

D

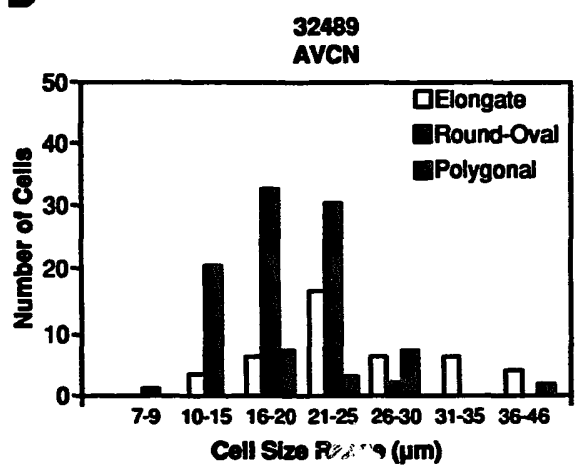

Fig. 6. The distributions of three cell groups as a function of cell size, (measured as the long axis), in contralateral PVCN (A and C) and AVCN (B and D). The upper (A and B) and lower (C and D) panels are from two different animals in which the WGA-HRP injections were located in DCN (animal 62988, see also Fig. 1A for injection location) and VCN (animal 32489, see also Fig. 1C for injection location), respectively.

Our round-to-oval cells include those categorized by Pirsig as 'round', ' round-to-oval' and 'oval' and may correspond to both the globular bushy and spherical bushy cells of Cant and Morest (1984), Moore (1986) and Hackney et al (1990), as well as some cells they classify as 'small'. Hackney et al. (1990) classify bushy

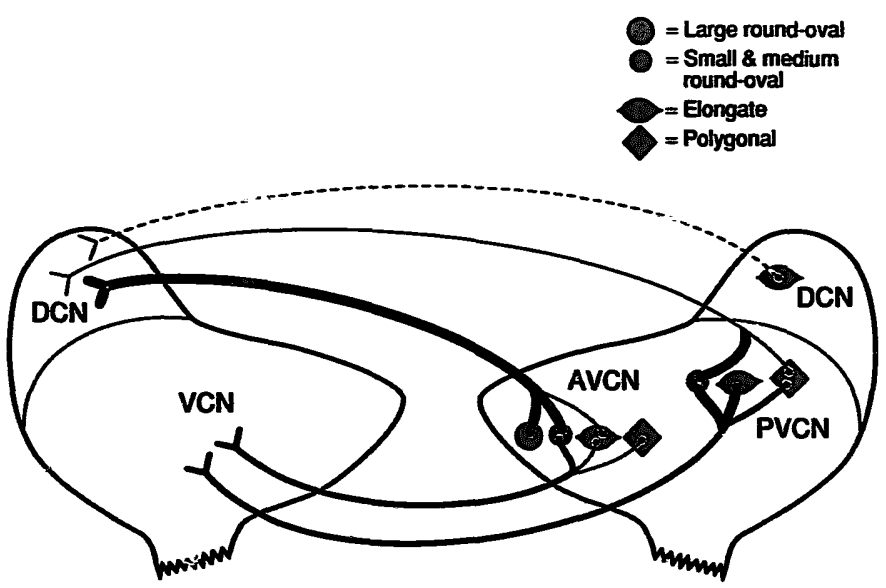

Fig. 7. Schematic diagram of projections of cell groups from each division of one CN to the opposite DCN and VCN. Line thickness represents the size of the projection. Large cells are defined as those $>25 \mu \mathrm{m}$ cells $15-23 \mu \mathrm{m}$ in size as 'spherical bushy' and those 28-30 $\mu \mathrm{m}$ in size as 'globular bushy'. The size range of round-to-oval cells in our study suggests that both spherical and globular bushy cells may project to the opposite cochlear nucleus. In addition, the eccentrically-placed nucleus, visible in lightly-labeled material (see Fig. 2E), and the presence of synaptic terminals totally surrounding the soma (unpublished electron microscopic observations) support this possibility. Most of our 28-30 $\mu \mathrm{m}$ round-to-oval cells projected only to dorsal cochlear nucleus, which suggests the possibility of globular bushy cells projecting preferentially to the opposite dorsal cochlear nucleus. This is the first study to suggest that spherical and globular bushy cells may have projection targets outside of the superior olivary complex. Other studies have demonstrated that spherical bushy cells project to the medial and lateral superior olivary nuclei, while the globular bushy cells project to the opposite medial nucleus of the trapezoid body and the dorsomedial periolivary nucleus (Stotler, 1953; Harrison and Warr, 1962; Harrison and Irving, 1966; Morest, 1968; van Noort, 1969; Tolbert et al., 1982). Both projections are excitatory, producing responses in the target nuciei which resemble those of the bushy cells (e.g., Goldberg and Brown, 1969; Guinan et al., 1972). In order to seriously entertain the possibility that some bushy cells may project to the 
contralateral cochlear nucleus, we need to exclude the possibility that some of these cells may be type II stellate cells, which also have somatic synaptic terminals (Cant, 1981). Further electron microscopy studies are currently underway to more fully resolve this question.

The heterogeneity of commissural cells found here was unexpected since previous papers have described only large, multipolar cells projecting from one cochlear nucleus to the other (Adams and Warr, 1976; Cant and Gaston, 1982; Wenthold, 1987). Cant and Gaston (1982) described labeling of large multipolar cells in the cat cochlear nucleus after injections of $30 \%$ HRP into different locations in the contralateral cochlear nucleus. However, examination of their Fig. 6 indicates that their labeled cells ranged from $11 \mu \mathrm{m}$ to $35 \mu \mathrm{m}$ in average diameter. This is actually not very different from the range of soma sizes observed in the present study, although the average diameter measurement would tend to be smaller than our long-axis measurements. Wenthold (1987) described labeling of 'large, multipolar' neurons in the contralateral cochlear nucleus of guinea pigs after large $30 \%$ HRP injections into dorsal cochlear nucleus or ventral cochlear nucleus. He defined 'large' neurons as those over $15 \mu \mathrm{m}$ in diameter. We would class $16-25 \mu \mathrm{m}$ diameter as medium. The small cells observed in the present study appear to be absent from his population of labeled cells. Although there is disagreement as to definitions of neuron size, the distribution of labeled cells in Wenthold's study was similar to that in the present study. Labeled cells were most abundant in caudal regions of anteroventral cochlear nucleus, but were also present in rostral parts of anteroventral cochlear nucleus and posteroventral cochlear nucleus. One explanation for the difference in labeled cell categories, besides a different criterion for considering a cell to be large, could relate to the use of WGA-HRP in our study versus HRP. WGA-HRP may be more readily taken up by nerve terminals and therefore may be more likely to label a greater number of cells than HRP. It is also possible that 'round' somata were not distinguished from polygonal or elongate somata in Wenthold's study or that some of the cells classed as round-to oval in our study could appear round because of the angle of the section. The large number of cells in this category, however, makes this explanation unlikely.

\section{Functional implications}

Cochlear nucleus neurons can be either excited or inhibited by contralateral acoustic stimulation. Neurons in the ventral division show inhibitory responses to contralateral sound (Pfalz, 1962; Pirsig et al., 1968; Klinke et al., 1969; Hochfeld, 1973), while those in the dorsal cochlear nucleus can be either excited or inhibited (Mast, 1970; 1973; Young and Brownell, 1976).
The dorsal cochlear nucleus neurons excited by contralateral stimulation show diverse patterns of spontaneous activity and diverse response patterns in terms of latency, discharge rate, and tuning curves (Mast, 1973), consistent with the heterogeneity of cells shown in this study to project to dorsal cochlear nucleus. Contralateral excitation of cells in the deep layers of dorsal cochlear nucleus (Mast, 1970, 1973) could be produced by round-to-oval cells in the opposite ventral cochlear nucleus especially in view of evidence suggesting that both bushy and stellate cells may employ excitatory amino acid transmitters (Altschuler et al., 1986; Godfrey et al., 1988). Since bushy cells in the anteroventral division send an excitatory projection to cells in the superior olivary complex (Goldberg and Brown, 1968; Guinan et al., 1972; Tsuchitani, 1977; Cant and Morest, 1979), it is likely that their projection to contralateral cochlear nucleus would also be excitatory. Of course, the excitatory response could also represent a release from inhibition mediated by an interneuron, or excitation via descending neurons in the superior olivary complex (Adams, 1983; Winter et al., 1989; Shore et al., 1991). The latencies of excitatory responses elicited by contralateral stimulation ranged from 13 to 145 ms (Hochfeld, 1973), sufficient time for several neurons to be involved.

Thus far, only inhibitory responses have been obtained in the ventral cochlear nucleus after contralateral acoustic stimulation (Pfalz, 1962; Pirsig et al., 1968; Klinke et al., 1969; Hochfeld, 1973). Since these responses can be blocked by strychnine (Pirsig et al., 1968), the pathway stimulated could involve the glycine-positive multipsiar cells observed by Wenthold (1987). If the round-to-oval cells in anteroventral cochlear nucleus correspond to the presumably excitatory bushy cells, it is difficult to explain the lack of excitatory responses to contralateral sound in the ventral cochlear nucleus. One explanation could be that small interneurons are initially excited, and they, in turn, inhibit the neurons from which extracellular responses are recorded. The relatively long latency of the effect in some neurons would be consistent with such an explanation. Olivocochlear neurons are another possible source contributing to these effects (see Godfrey et al., 1988).

\section{Species differences in the contralateral connection}

The guinea pig differs from other species in some aspects of the organization of the cochlear nucleus and its connections. Hackney et al. (1990) have shown a higher predominance of bushy cells in the ventral cochlear nucleus of the guinea pig than the cat. In the present report, relatively large numbers of labeled round-to-oval cells in the ventral cochlear nucleus, compared with none in the cat (Cant and Gaston, 1982), might correlate with an increase in the number 
of bushy cells reported for the guinea pig. The possible species differences in the projections from contralateral cochlear nucleus would parallel findings that brainstem projections from the superior olivary complex to the cochlea and cochlear nucleus are different from those in the cat (Winter et al., 1989; Shore et al., 1991). There may also be less of a commissural cochlear nucleus pathway in the rat than in the guinea pig (unpublished observations).

The findings of this study indicate that the pathway projecting from one cochlear nucleus to the other is diverse and complex, involving heterogeneous cell types which end in somewhat different target regions. The complexity of responses obtained from neurons in ventral and dorsal cochlear nucleus to contralateral acoustic stimulation is consistent with the heterogeneity of cells and projection targets shown here. Detailed physiological studies, with precise knowledge of elect-ode locations, are essential to elucidate further the function and organization of this potentially important pathway.

\section{Acknowledgements}

This work was supported by NIH grants DC00172 and DC00078 to D. Godfrey and R. Altschuler. We are grateful to Nell Cant and John Guinan for valuable reviews of this manuscript, and Joanne Bonneau, Becky Szczygiel and Irene Young for technical assistance.

\section{References}

Adams, J.C. (1983) Cytology of periolovary cells and the organization of their projections in the cat. J. Comp. Neurol. 215, 275-289.

Adams, J.C. and Warr, W.B. (1976) Origins of axons in the cat's acoustic striae determined by injection of horseradish peroxidase into severed tracts. J. Comp. Neurol. 11, 49-62.

Altschuler, R.A., Betz, H., Parakkal, M.H., Reeks, K.A. and Wenthold, R.J. (1986) Identification of glycinergic synapses in the cochlear nucleus through immunocytochemical localization of the postsynaptic receptor. Brain Res. 369, 316-320.

Brawer, R.J., Morest, D.K. and Kane, E.C. (1974) The neuronal architecture of the cochlear nucleus of the cat. J. Comp. Neurol. $155,251-300$.

Cant, N.B. (1981) The fine structure of two types of stellate cells in the anterior division of the anteroventral cochlear nucleus of the cat. Neuroscience 6, 2643-2655.

Cant, N.B. and Gaston, K.C. (1982) Pathways connecting the two cochlear nuclei. J. Comp. Neurol. 212, 313-326.

Cant, N.B. and Morest, D.K. (1979) The bushy cells in the anteroventral cochlear nucleus of the cat. A study with the electron mciroscopoe. Neuroscience 4, 1925-1945.

Cant, N.B. and Morest, D.K. (1984) The structural basis for stimulus coding in the cochlear nucleus of the cat. In: C.I. Rerlin (Ed.), Hearing Science. College-Hill Press, San Diego. pp. 371-421.

Godfrey, D.A., Parli, J.A., Dunn, J.D. and Ross, C.D. (1988) Neurotransmitter microchemistry of the cochlear nucleus and superior olivary complex. In: J. Syka and R.B. Masterton (Eds.), Auditory Pathway, Plenum Press, New York, pp. 107-121.

Goldberg, J.M. and Brown P.B. (1969) Response of binaural neurons of dog superior olivary complex to dichotic tonal stimuli: Some physiological mechanisms of sound localization. J. Neurophysiol. $32,613-636$,

Guinan, J.J., Guinan, S.S. and Norris, B.E. (1972) Single auditory units in the superior olivary complex. I. Responses to sounds and classification based on physiological properties. Int. J. Neurosci. 4, 101-120.

Hackney, C.M., Osen, K.K. and Kolston, G. (1990) Anatomy of the cochlear nuclear complex of guinea pig. Anat. Embryol. 182, 123-149.

Harrison, J.M. and Irving, G. (1966) Ascending connections of the anterior ventral cochlear nucleus in the rat. J. Comp. Neurol. $126,15-42$.

Harrison, J.M. and Warr, W.B. (1962) A study of the cochlear nuclei and ascending auditory pathways to the medulla. J. Comp. Neurol. 119, 341-379.

Hochfeld, P.R. (1973) Binaural interactions in the cat's cochlear nucleus. Master's thesis. Department of Electrical Engineering, M.I.T., Cambridge, MA.

Klinke, R., Boerger, G. and Gruber, J. (1969) Studies on the functional significance of efferent innervation in the auditory system: Afferent neuronal activity as influenced by contralaterally applied sound. Pfluegers Arch. 306, 165-175.

Mast, T.E. (1970) Binaural interaction and contralateral inhibition in dorsal cochlear nucleus of the chinchilla. J. Neurophysiol. 33, 108-115.

Mast, T.E. (1973) Dorsal cochlear nucleus of the chinchilla: Excitation by contralateral sound. Brain Res. 62, 61-70.

Mesulam, M.M. (1978) Tetramethyl benzidine for horseradish percxidase neurochemistry: a non-carcinogenic blue reaction-product with a superior sensitivity for visualizing neural afferents and efferents. J. Histochem. Cytochem. 26, 106-117.

Moore, J.K. (1986) Cochlear nuclei: Relationship to the auditory nerve. In: R.A. Altschuler, D.W. Hoffman and R.P. Bobbin (Eds.), Neurobiology of Hearing: The Cochlea. Raven Press. New York, pp. 283-301.

Morest, D.K. (1968) The collateral system of the medial nucleus of the trapezoid body of the cat, its neuronal architecture and relation to the olivo-cochlear bundic. Brain Res. 9, 288-311.

Osen, K.K. (1969) Cytoarchitecture of the cochlear nuclei in the cat. J. Comp. Neurol. 136, 453-484.

Pfalz, R.K.J. (1962) Centrifugal inhibition of afferent secondary neurons in the cochlear nucleus by sound. J. Acoust. Soc. Am. 34, $1472-1477$.

Pirsig, W. (1968) Subdivisions, cell morphology and synaptic endings in the ventral cochlear nucleus in the guinea pig. Archi. Klin. Exp. Phren-Nasen-Kehlkopfheil. 192, 333-350.

Pirsig, W., Pfalz, W. and Sadanaga, M. (1968) Postsynaptic auditory crossed efferent inhibition in the ventral cochlear nucleus and its blocking by strychnine nitrate (guinea pig). Kumamoto Med. J. $21,75-82$.

Shore, S.E. and Nuttall, A.L. (1985) High synchrony cochlear compound action potentials evoked by rising frequency-swept tone bursts. J. Acoust. Soc. Am. 78, 1286-1295.

Shore, S.E., Helfert, R.H., Bledsoe, S.C., Altshuler, R.A. and Godfrey, D.A. (1991) Descending projections to the guinea pig cochlear nucleus. Hear. Res. 52, 255-268.

Stotler, W.A. (1953) An experimental study of the cells and connections of the superior olivary complex of the cat. J. Comp. Neurol. 98, 401-431.

Tolbert, L.P. and Morest, D.K. (1982) The neuronal architecture of the anteroventral cochlear nucleus of the cat in the region of the cochlear nerve root: Golgi and Nissl methods. Neuroscience 7, 3013-3068. 
Tsuchitani, C. (1977) Functional organization of lateral cell groups of cat superior olivary complex. J. Neurophysiol. 40, 296-318.

van Noort, J. (1969) The anatomical basis for frequency analysis in the cochlear nucleus complex. Psychiat. Neurol. Neurochir. 72, 109-114.

Wenthold, R.J. (1987) Evidence for a glycinergic pathway connecting the two cochlear nuclei: An immunohistochemical and retrograde transport study. Brain Res. 415, 183-187.
Winter, I.M, Robertson, D. and Cole, K.S. (1989) Descending projections from auditory brainstem nuclei to the cochlea and cochlear nucleus of the guinea pig. J. Comp. Neurol 280, 143-157.

Young, E.D. and Brownell, W.E. (1976) Responses to tones and noise of single cells in dorsal cochlear nucleus of unanestheized cats. J. Neurophysiol. 39, 282-300. 